\title{
Creating Rich and Representative Personas by Discovering Affordances
}

\author{
Mostafa Mesgari, Chitu Okoli, and Ana Ortiz de Guinea
}

\begin{abstract}
During the last decade, information system designers have used the persona technique to put user needs and preferences at the center of all development decisions. Persona development teams draw on qualitative data, quantitative data or a combination of both to develop personas that are representative of the target users. Despite the benefits of both approaches, qualitative methods are limited by the cognitive capabilities of the experts, whereas quantitative methods lack contextual richness. To gain the advantages of both approaches, this article suggests a mixed qualitative-quantitative approach to create user personas based on the patterns of the affordances they actualize rather than merely the actions they take. It enriches personas by referring to the purposes fulfilled through affordance actualizations, and it grounds personas in readily available objective log data. This study illustrates the practical value of the proposed methodology by empirically creating personas based on real user data. Furthermore, it demonstrates its value by having practitioners compare the suggested method to that of qualitative-only and quantitative-only methods.
\end{abstract}

Index Terms-Personas, affordances, mixed qualitative and quantitative methods, user modeling, interview, card sorting, cluster analysis, systems design and implementation, design and evaluation of IT infrastructure, questionnaire surveys

\section{INTRODUCTION}

$I^{\mathrm{N}}$ $\mathrm{N}$ trying to understand the nature and the needs of information system users, designers often develop personas to characterize their target user groups. A persona is a "precise description of a user's characteristics and what he/she wants to accomplish" [1, p. 439]. Persona development teams usually draw on either qualitative or quantitative data to understand users and develop representative personas [2], [3]. While both qualitative and quantitative methodologies appear to have benefits, each method alone has its own limitations. Qualitative methods are criticized for being limited to the cognitive capabilities of the development team [4], and quantitative methods lack context and richness [5].

To address the issue, this article draws on the theory of affordances to suggest a mixed qualitative-quantitative approach to create personas based on patterns of affordance actualization in user behaviors. It qualitatively identifies the system affordances and the actions actualizing those affordances and then quantitatively identifies major patterns of affordance actualization in user $\log$ data.

Personas have been part of Human-Computer Interaction (HCI) and User-Centered Design practice and research for more than a decade [6]-[8]. Software Engineering research has also increasingly incorporated personas. Aoyama [9] used field studies and conjoint analysis to develop personas of mobile phone

- Mostafa Mesgari is with the Love School of Business, Elon University, NC, U.S.A.E-mail:mmesgari@elon.edu.

- Chitu Okoli is with SKEMA Business School, Paris, France. E-mail: chitu.okoli@skema.edu.

- Ana Ortiz de Guinea is with the Department of Strategy and Information Systems, Deusto Business School, Universidad de Deusto, Spain; and with the Department of Information Technologies, HEC Montréal, Canada. Email:ana.ortizdeguinea@deusto.es,ana.ortiz-de-guinea@hec.ca.

Please note that all acknowledgments should be placed at the end of the paper, before the bibliography (note that corresponding authorship is not noted in affiliation box, but in acknowledgment section). users in various scenarios as a way of carrying out requirements engineering. His "Hanoko" method was able to identify new kinds of personas in that context that others had not previously identified. Haikara [10] described a case that incorporated persona design as a means of assuring usability and interaction in an agile software development process. The developers developed the personas qualitatively and interactively with the agile process, but as personas were a new idea to both the developers and the users of that particular project, it was not easy to incorporate them. Seffah et al. [11] used personas to better understand user profiles in an e-maintenance context so as to better understand users' concrete needs and hence provide a better user experience. Faily and Lyle [12] provided four guidelines for enhancing software tools to support the creating and maintenance of personas: "make persona characteristics explicit" (p. 2); "integrate [tools to support] qualitative data analysis" (p. 3); incorporate capabilities to save, export and import personas files; and enable the revision control of such persona description files. Ford et al. [13] developed personas of software engineers (rather than users) so as to understand their various competencies and preferences in project tasks. Their identified personas "include those with focused debugging abilities, engineers with an active interest in learning, experienced advisors who serve as experts in their role, and more". By better understand types of software engineers, project managers should be equipped to make better task assignment decisions and hence improve the success of their software projects.

This study contributes to User-Centered Design practice and research by proposing a methodology to create richer and more credible personas. It extends the Software Engineering literature by incorporating behavioral elements of users in persona creation, while retaining strong objective elements based on their actual system usage. It bridges the behavioral Information Systems (IS) research and the design-oriented HCI research to bring fruitful insights for both. For IS research, this study provides a way 
to analyze user behavior in relation to the Information Technology (IT) artifact. For HCI research, it suggests analyzing user action data at a more behavioral level in terms of the affordances that users actualize.

Our methodology applies best to legacy systems (or systems already in use) that require maintenance and new development. Such systems are paramount because they represent around $70 \%$ of corporate business systems today [14]. In fact, 9 out of 10 managers capable of making decisions about IT affirm that legacy systems prevent them for harnessing the benefit of other technologies [15]. Even more, the majority of governmental agencies spend $90 \%$ or more - which represents approximately 72 billion dollars - of their Information Technology (IT) on operations and maintenance of legacy systems [16], [17]. In terms of different phases of the software development life cycle, maintenance reportedly composes $67 \%$ of the costs, and it includes new functionality developments [18]. In fact, Glass [19] further breaks down the software development costs by his rule of " $60 / 60$ " meaning $40 \%$ to $80 \%$ (average of $60 \%$ ) of the software development costs consists of the maintenance costs, and $60 \%$ of maintenance costs consists of software enhancement and upgrades compared to just $17 \%$ for error correction. This highlights the essential importance of the legacy system enhancement activities for which our methodology could be applicable.

To demonstrate the practical value of the suggested methodology, we empirically examine student use of Moodle, a learning management system (LMS), in a Canadian business school and identify three personas that demonstrate unique patterns of affordance actualization. The student sample represents the actual professional user population for this study; it is not a substitute for some other user population. Moreover, this study does not intend to generalize the findings over and above the specific implementation of the system studied. To demonstrate the advantages of the proposed method, we also use our empirical data to create quantitative-only personas, and we draw on independently developed qualitative-only personas. We have seven practitioner experts compare the affordance-based personas to the other two and thoroughly discuss the implications for research and practice.

\section{Developing User Personas}

Since Alan Cooper [20] first suggested the notion of user personas, personas have become an important technique to put users at the center of every system development project and make the resulting system more user friendly [21]-[23]. Personas give the development team a better idea of who the target users are, what they need, and for what they use the system [1]. A persona is an "archetypical representation of customers or users" [24, p. 545]. It is a fictional character that puts a face on a coherent user data structure. Personas serve multiple purposes for the system development team. First, they enable the team to build a shared understanding of user characteristics, needs and behaviors. A shared understanding of the target user group facilitates and justifies design decisions made by the team members [25]. Second, the fictional characters facilitate communication of the design and its rationale not only among the development team members but also between the design team and other stakeholders including testers, managers, marketers, and customers [23]. Third, per- sonas can effectively engage team members in the system development process [21]. They provide the boundary object [26] that designers, programmers, testers and others can understand, relate to, and engage with during the development process.

The user data represented by personas may refer to either user demographics (e.g. age, occupation and education), psychographics (e.g. lifestyle, goals, needs and intentions), or user behavior (e.g. user interaction with the system and their click stream). Various qualitative and quantitative methods draw on these user data to create representative user personas. As an illustration, Table 1 represents the personas that Microsoft created for Office 365 Enterprise application users.

Table 1. Microsoft Office 365 Enterprise personas

\begin{tabular}{|c|c|}
\hline $\begin{array}{c}\text { Persona } \\
\text { Name }\end{array}$ & Description \\
\hline Transforming & $\begin{array}{l}\text { - Customers with propensity to increase/decrease em- } \\
\text { ployee count regularly } \\
\text { - Require agile scalability and flexibility } \\
\text { - E.g. acquisitions, layoffs, temporary seasonal work- } \\
\text { ers }\end{array}$ \\
\hline Cost Saver & $\begin{array}{l}\text { - Customer primarily looking to cut costs, value a fo- } \\
\text { cus on TCO } \\
\text { - Interested in moving from capex to opex }\end{array}$ \\
\hline $\begin{array}{l}\text { Google Com- } \\
\text { pete }\end{array}$ & $\begin{array}{l}\text { - Customer in active discussions with Google } \\
\text { - Greater focus on collaboration and messaging work- } \\
\text { loads }\end{array}$ \\
\hline Task Worker & $\begin{array}{l}\text { Population of structured task workers who don't } \\
\text { have dedicated PCs } \\
\text { - Prevalent in retail, hospitality, manufacturing and } \\
\text { healthcare industries } \\
\text { - E.g. Manufacturing Plant Floor worker, Nurse, } \\
\text { Barista }\end{array}$ \\
\hline $\begin{array}{l}\text { Dated Envi- } \\
\text { ronment }\end{array}$ & $\begin{array}{l}\text { - Customers on older versions (N-2+) of Exchange, } \\
\text { SharePoint and Office who don't have new version } \\
\text { rights } \\
\text { - Want to adopt new business productivity capabilities } \\
\text { and stay current } \\
\text { - E.g. Customer deployed on Exchange } 2003 \text { without } \\
\text { Software Assurance }\end{array}$ \\
\hline
\end{tabular}

Personas copied from Columbus [29]

Qualitative approaches to persona development are mainly dependent on interviews and observational data referring to user psychographics. Ethnographic and participatory observation can be useful for revealing existing user practices, perspectives, and objectives within the context [21], [24]. Grounded theory provides a systematic analysis of user interview data and can create personas based on the common themes that reveal the major characteristics of the target user group [3]. Affinity diagrams help in finding the themes in qualitative data by grouping similar statements into affinities and relating them together [23], [24], [27]. Expert panels are useful in acquiring rich qualitative information about user perspectives and practices that can be analyzed later using grounded theory or affinity diagrams [27]. Latent semantic analysis quantitatively analyzes the textual qualitative data to come up with the recurring themes that form the personas [2], [28]. These methodologies are popular because of the rich contextual information they provide about users and their actions. However, these qualitative approaches rely on manual qualitative analysis of the data which is heavily dependent on the researcher's cognitive capabilities and takes much time and thus limits the amount of data that they can analyze for creating personas. As a result, except for Latent Semantic Analysis which 
relies on text mining techniques, the other qualitative approaches normally create personas based on data from no more than a handful of users. This limits the representativeness of the qualitative personas.

Quantitative approaches draw mainly on user surveys and computer log data that refers to user demographics or user actions and behaviors. They involve various multivariate data analysis techniques for finding trends in data and identifying homogenous groups of users as the bases for the personas. Some popular quantitative analysis methods are factor analysis [30] and principal component analysis [2], [31], both of which reduce the number of independent variables in the data to come up with the minimum number of factors that explain most of the variance in the user dataset, and then create the major personas with these identified factors. Cluster analysis [2], [32], [33], correspondence analysis [4] and association rule mining [33] group related users based on homogeneity in their demographics and characteristics; such groups constitute the personas. The main advantage of quantitative methods is to build personas based on information about large numbers of users believed to be representative of the user target population [2]. Moreover, quantitative personas are well grounded in user data, which makes it easy to communicate the personas to a development team due to traceable user data [24]. However, the limited context provided by the quantitative data means that quantitative methods lack rich understanding about who the personas are, what they need, and why they behave in specific ways. Moreover, in many cases the factors or clusters resulted in quantitative analysis are not easily interpretable, which makes it hard for researchers to translate them into coherent personas. In other words, the persona designer must consider the meaning and intention behind those actions and how they are related. In fact, sometimes it may be impossible to find a plausible rational justification for why certain actions are used by the same persona. Because of these challenges, quantitative approaches are generally less popular than qualitative ones.

Despite the respective benefits of the qualitative and quantitative methodologies, each method alone has certain limitations. For example, the quantitatively developed personas based on user actions and log data have been criticized for excluding the context and the users' preferences and motivations. They focus on users' actions without taking into consideration that actions occur within the context of users' intentions and goals. On the other hand, although qualitative persona development methods are richer in terms of context, they take much more time and resources to develop [30]. Moreover, qualitative methods require a considerable effort in induction from specific and context rich users' information to an abstract representation of a persona. Thus, they are criticized for a potential lack of credibility and rigor [4].

The limitations of using each method alone have encouraged some scholars to combine quantitative and qualitative methodologies together e.g. [30]-[32]. Mixed-methods approaches help to overcome the weakness of any single method by compensating one with the strengths of another [34]. However, the existing attempts do not seem to realize the full advantages of a mixedmethods approach to identify user personas. They typically group users into personas based only on quantitative data and then use qualitative data to add narratives and enrich persona descriptions. In other words, they do not use qualitative data for identifying the personas, but rather for enriching them after they have already identified the personas quantitatively. Table 2 summarizes the advantages and disadvantages of the existing three approaches to persona creation.

Table 2. Existing approaches and methodologies for persona creation

\begin{tabular}{|c|c|c|c|}
\hline Approaches & Methodologies & Advantages & Disadvantages \\
\hline $\begin{array}{l}\text { Quantita- } \\
\text { tive }\end{array}$ & $\begin{array}{l}\text { - Factor analysis } \\
\text { - Principal com- } \\
\text { ponent analysis } \\
\text { - Cluster analysis } \\
\text { - Correspondence } \\
\text { analysis } \\
\text { - Association rule } \\
\text { mining } \\
\end{array}$ & $\begin{array}{l}\text { - Grounded in } \\
\text { data from } \\
\text { large user } \\
\text { community } \\
\text { - Easy to ex- } \\
\text { plain }\end{array}$ & $\begin{array}{l}\text { - Lack of contex- } \\
\text { tual richness }\end{array}$ \\
\hline Qualitative & $\begin{array}{l}\text { - Ethnography } \\
\text { - Grounded theory } \\
\text { - Affinity dia- } \\
\text { grams[12], [13], } \\
\text { [17] } \\
\text { - Expert panels } \\
\text { - Latent semantic } \\
\text { analysis }\end{array}$ & $\begin{array}{l}\text { - Rich contex- } \\
\text { tual infor- } \\
\text { mation }\end{array}$ & $\begin{array}{l}\text { - Potential lack of } \\
\text { credibility and } \\
\text { rigor } \\
\text { - Take very much } \\
\text { time and many } \\
\text { resources to de- } \\
\text { velop } \\
\text { - Quality is incon- } \\
\text { sistent across } \\
\text { different per- } \\
\text { sona designers }\end{array}$ \\
\hline $\begin{array}{l}\text { Current } \\
\text { Mixed } \\
\text { Quantita- } \\
\text { tive and } \\
\text { Qualitative }\end{array}$ & $\begin{array}{l}\text { Creating groups } \\
\text { of users quanti- } \\
\text { tatively and add- } \\
\text { ing richness to } \\
\text { those groups } \\
\text { qualitatively }\end{array}$ & $\begin{array}{l}\text { - Grounded in } \\
\text { data from } \\
\text { large user } \\
\text { community } \\
\text { - Rich contex- } \\
\text { tual infor- } \\
\text { mation }\end{array}$ & $\begin{array}{l}\text { - Groups are } \\
\text { made based } \\
\text { solely on quanti- } \\
\text { tative data } \\
\text { - Do not leverage } \\
\text { the full potential } \\
\text { of qualitative } \\
\text { data }\end{array}$ \\
\hline
\end{tabular}

In the following sections, we suggest a mixed-methods approach based on the theory of affordances that uses both qualitative and quantitative data to group users and identify personas based ontheir affordance actualization patterns, and that aims to resolve the identified shortcomings in current persona development approaches.

\section{Creating User Personas Based On AFFORDANCES}

The theory of affordances [35] explains individual behavior in terms of affordances, defined as the "action possibilities" provided by the environment to an individual. Affordances are functional properties of the individual-environment system [36]. Beyond mere actions, they refer to some activity, purpose or task. They are the root of individual perceptions and actions. People choose to actualize affordances through actions embedded in the realm of their intentions and purposes.

Affordance theory has been adapted to various areas of technology-organization research [37]-[40]. Drawing on this theory, we propose creating personas based on affordance actualization patterns grounded in users' intentions and purposes, rather than on an exclusive focus on users' actions. What guides users' behaviors is the affordances they perceive and thus actualize based ontheir direct actions, intentions and purposes. That is, actions do not occur in a vacuum, but within the individual-environment context. In other words, users interact with the system and actualize affordances that are based on the goals they want to attain. This approach avoids simply analyzing users' actions without understanding the intended purposes of those actions.

We propose examining user behavior at the affordance level 
of analysis and grouping them according to the pattern of affordances they actualize. That is, instead of clustering users only based on their action data, we first aggregate various actions into their related affordances and then cluster the users according to the affordances they have actualized. Clusters based on affordance actualizations take into consideration users' intentions and goals, unlike clusters that are based on actions alone. At the same time, the cluster analysis adds predictability and rigor to the qualitative approach by aggregating actions into their related affordances. Furthermore, while current methods like factor analysis identify user actions based on statistical correlations and produce clusters that are difficult to interpret, the proposed method aggregates user actions based on data-driven, meaningful affordances. Thus, we believe that our methodology offers richer personas over quantitative-only methods and more representative ones over qualitative-only approaches.

In our approach, we extract major affordances by qualitatively analyzing in-depth interviews with users. Next, we use the card sorting technique to categorize users' actions into affordances. Finally, we cluster users according to the affordances they actualize, rather than merely according to the actions they take. The proposed method uses both qualitative and quantitative data to develop personas based on specific system affordance actualization patterns.

It is important to note the reasons for the sequence of research methods that we will present to build personas. First, to extract and identify affordances, we use qualitative methods because they allow for the exploration and discovery of relevant information of users whose behaviors and goals are not well known. The qualitative phase reveals major reasons that guide user behavior while using the system. Second, based on the previous information and data logs, we then use quantitative methods to add precision to the personas. The quantitative phase identifies precise patterns of behavior extracted from a large user community. Thus, the mixed method approach takes the strengths of each method at the right time to compensate for the weakness of any single method or a mixed method that sequences quantitative and then qualitative criteria [41]. The following subsections describe this approach in detail.

\subsection{Extracting Affordances}

Affordances are action possibilities that guide user behavior. As explained earlier, because they are functional properties of the technological environment that supports users' purposes and tasks [42], they put actions within the context of users' purposes. Thus, whereas actions in themselves do not necessarily indicate any specific purpose, affordances, by definition, encompass the users' purposes and motives when interacting with a system. For instance, "sitting down" as an action makes no reference to the person's purpose. In contrast, the affordance "resting" includes the purpose fulfilled by a person when sitting on a chair. It is important to note that technology affordances refer only to those affordances related to the focal technology itself, not to the "complete" set of affordances of the environment.

To empirically extract the affordances of a new system, we suggest drawing in depth on users who are well experienced with the technological domain [43], hence the need for qualitative approaches. Because affordances are functional in nature, it is important to draw upon users who have experience with the technical environment as well as the social context in which the use of a system takes place. Qualitative analysis of rich interview data with experienced users is extensively used to extract affordances of new technological settings [44]-[46]. We believe qualitative interviews with experienced users is effective in identification of the affordances because it reveals user perspectives of the system and how it enables them to act and fulfil their purposes. Depending on the extensiveness of the system, a few indepth interviews with experienced users is usually sufficient to detect most important system affordances. To extract affordances, interview data needs to be qualitatively coded to identify tasks, activities and purposes. The coded data is then grouped into meaningful affordances. When affordances are identified, they need to be clearly defined so that they can be easily differentiated from each other. Clear definition of affordances is the key to the next step for identifying the actions that actualize the affordances.

\subsection{Identifying Actions That Actualize Affordances}

In the next step, we need to identify the actions that actualize the affordances; in other words, which actions actualize which affordances? Experienced users who have been performing those actions are the credible experts who can reveal the context and purpose of their actions, and clarify which affordance is actualized by each action. Card sorting is the technique to evaluate how several experts sort the actions into affordances. If the expert users sort actions consistently and with a high level of agreement into the affordances, that reveals what the actions consistently mean to users and which affordance they actualize. This is a unique technique that evaluates affordance actualization by actions from the users' perspective, rather than from the designers'.

In that regard, we first need to prepare a list of actions available to the user. Typically, we can obtain this from user log data. We should then clearly define each action so that anyone reading the action definitions would have the same understanding of what each action refers to. Next, we should recruit a few experienced users to identify which actions actualize which affordances through a card sorting exercise [47]. We provide these users with a list of actions (obtained from user logs) and a list of affordances (obtained from in-depth interviews), then ask them to specify which affordance they are actualizing when they take any of the specific actions. We should then use inter-rater reliability measures, such as Fleiss' kappa [48], [49], to demonstrate the degree of agreement among users about which action actualizes which affordance.

In many cases, the first round of card sorting would highlight disagreements on specific actions and affordances. We, the researchers, need to examine any conflicting items to understand the reasons for disagreement. We may ask the users to explain their categorization to help the researchers to improve their identification and definition of actions and affordances. We should repeat the card sorting exercise with new sets of experienced users until they reach acceptable agreement on the set of actions that actualize each of the affordances.

\subsection{Creating Personas by Identifying Patterns of Affordance Actualization}

In the third step, we need to identify the patterns in affordance actualization, so they represent the user personas. Quantitative analysis of the user log data and the affordances actualized reveals the patterns based on data from a large user community, so 
the personas will be grounded in and representative of actual user behavior. Cluster analysis examines a large set of user log data and identifies clusters of users who actualize affordances in similar ways. For that purpose, we should examine the user log data, where we aggregate user actions into the affordances they actualize, and apply a statistical clustering technique to identify user groups based on their patterns of affordance actualization.

The specific choice of clustering method and distance measure is highly dependent on the goals of the study; it can significantly change the user grouping results and the personas created. To select the best distance measure, we need to make an important distiction: should we group users according to their level of affordance actualization or according to the pattern of affordance actualization? In other words, should users with similar levels of affordance actualization form a persona, or should users with similar proportional affordance actualizations? In the former case, using Euclidean distance would be preferable; but in the latter case, the Pearson correlation distance would be advised. Since understanding user behavior and creating personas is mostly about pattern of behavior than its quantity, we advise Pearson correlation as the suitable distance measure for persona studies.

To illustrate this proposed methodology, we follow with a complete empirical demonstration.

\section{ILLUSTRATION Study: MOOdLE User Personas}

Moodle is an open-source LMS that is actively developed by Moodle HQ and a large community of volunteer contributors. As of May 2016, there were over 75,000 Moodle sites in 225 countries, running over 9 million courses for more than 85 million users (https://moodle.net/stats/). Whereas Moodle defines certain user "roles" (e.g. Student, Teacher and Teaching Assistant), these roles are essentially user privilege profiles. They do not attempt to accommodate how users with the same role might possibly use their privileges in significantly different ways - which is the focus of personas in this study.

To demonstrate the applicability of the proposed persona development methodology and to help the Moodle community to improve its design and development, we use the suggested affordance-based mixed-methods technique to create the user personas representative of a sample community of Moodle users. According to the guidelines of Compeau et al. [50], the use of a student sample is ideally suitable for this study for two reasons. First, the student sample is not a proxy for some professional user group, but it represents the actual user group for the purposefully chosen system of this study (i.e. Moodle). Second, this study does not aim to generalize the findings over and above the specific implementation of the system examined. In fact, the purpose of the empirical inquiry is to illustrate the practicality of the suggested method and the value of the insights derived from it. WE draw the sample from students in a Canadian business school with over 9,000 students that was in the process of switching from the former LMS that the school had used (FirstClass) to Moodle. Creating Moodle user personas could help guide instructors in the school to design their Moodle pages to support major personas. Moreover, the Moodle community may obtain insights on how certain implementations of Moodle guide users' behavior.
Before this main study, we conducted a pilot study to test the procedure. After the pilot, we conducted the full study from July to December 2015. We conducted 17 interviews in total with experienced student users of Moodle to identify the major affordances provided by Moodle to the student community. Next, we conducted two rounds of the card sorting technique to assign user actions to the identified affordances. Then we used cluster analysis to analyze the student $\log$ data to find the patterns in student behavior and how they actualize various Moodle affordances relative to each other. The identified clusters can form the basis for creating the user personas for the Moodle developer community.

\subsection{Step 1: Extracting Moodle Affordances with Interviews}

To empirically extract the affordances of a new setting, users should be consulted who are well experienced with the technological domain [43], [44]. Since affordances have social aspects, understanding them requires consulting those who have extensive experience with the technical environment as well as the social context in which the technology is used.

To recruit experienced users, we invited about 400 undergraduate students of a Canadian university by email to register for an interview session about their experiences with Moodle if they had completed at least two courses that used Moodle. We offered a \$15 compensation to participants for their time. 43 students registered to participate in the study by filling in a form that explained the nature and extent of their experience. Of those who registered, we interviewed the 17 students most experienced with Moodle; we stopped further interviews when we reached a saturation point after 17 interviews [51]. Table 3 displays the demographic characteristics of the 17 interviewees.

Table 3. Demographic characteristics of interviewees

\begin{tabular}{|c|c|c|}
\hline \multicolumn{2}{|c|}{ Demographic variable } & Frequency \\
\hline \multirow{2}{*}{ Gender } & Male & $53.94 \%$ \\
\hline & Female & $47.06 \%$ \\
\hline \multirow{8}{*}{ Major } & Accountancy & $23.53 \%$ \\
\hline & $\begin{array}{r}\text { Business Technology Man- } \\
\text { agement (BTM) }\end{array}$ & $17.65 \%$ \\
\hline & Finance & $11.76 \%$ \\
\hline & $\begin{array}{r}\text { Human Resource Manage- } \\
\text { ment }\end{array}$ & $5.88 \%$ \\
\hline & International Business & $5.88 \%$ \\
\hline & $\begin{array}{r}\text { Marketing } \\
\end{array}$ & $23.53 \%$ \\
\hline & $\begin{array}{r}\text { International Business \& } \\
\text { Marketing } \\
\end{array}$ & $5.88 \%$ \\
\hline & Marketing \& BTM & $5.88 \%$ \\
\hline \multirow{4}{*}{$\begin{array}{l}\text { Year in } \\
\text { School }\end{array}$} & $1^{\text {st }}$ year & $17.65 \%$ \\
\hline & $2^{\text {nd }}$ year & $23.53 \%$ \\
\hline & $3^{\text {rd }}$ year & $53.94 \%$ \\
\hline & $4^{\text {th }}$ year & $5.88 \%$ \\
\hline \multicolumn{2}{|c|}{$\begin{array}{r}\text { Average number of courses completed us- } \\
\text { ing Moodle }\end{array}$} & $\begin{array}{l}10.06 \quad \text { (s.d. } \\
5.47)\end{array}$ \\
\hline \multicolumn{2}{|c|}{ Number of Moodle visits per week/course } & $\begin{array}{l}6.12 \quad \text { (s.d. } \\
6.00)\end{array}$ \\
\hline \multicolumn{2}{|c|}{$\begin{array}{r}\text { Time spent on Moodle per day (in } \\
\text { minutes) }\end{array}$} & $\begin{array}{l}25.38 \quad \text { (s.d. } \\
31.38)\end{array}$ \\
\hline
\end{tabular}


We minimized any possible student response bias by the following three considerations: 1) no participant was a student of the interviewer. 2) they read and signed a consent form that informed them that none of their input would be shared with their instructors. and 3) the interviewer approached the participants as a researcher looking into ways to improve student experience of Moodle, and many felt comfortable to share even negative feelings and experiences.

We used a semi-structured interview guide that started with general questions about the students' studies, Internet experience and experience with Moodle or any other learning platform. Then we asked them about how they liked or disliked Moodle and other general questions to encourage them to talk about their experiences, possibilities, activities and purposes on Moodle. We also asked them to describe their everyday experience on Moodle. To help them remember specific experiences, we asked them to compare their experience on Moodle across various courses. Moreover, we asked them to compare their experience on Moodle with their experience on other learning platforms such as FirstClass. At the time of this study, the school was transitioning from FirstClass to Moodle as its LMS; while some instructors were still using FirstClass, most instructors were using Moodle, so the interviewees had experience with both. Thus, many of them were keenly conscious of their experience in transitioning to Moodle, so they could answer from the perspective of discovering new affordances on Moodle. Interview questions about comparing their experiences with the two systems were quite helpful for the interviewees to remember many specific experiences they had. During the interviews, we were highly focused on their experiences, actions, activities, possibilities, and purposes pursued and fulfilled by users while they were on Moodle.

To analyze the data, we had the recorded interviews transcribed and transferred to Nvivo 10 software for qualitative data analysis. We followed qualitative data analysis guidelines [52] to openly code the data into every possible action, task, and purpose the interviewees described. In particular, we were cautious about letting our preconceptions from the pilot study affect our coding for the main study; so to remain close to the data, we used "in vivo" codes, that is, the exact terms used by the interviewees [52]. Initial open coding of the transcribed data by the principal researcher resulted in 33 codes found in 456 quotations. Since we reached theoretical saturation, we did not continue collecting further interview data. To assure the trustworthiness of our coding, we had a second coder use our coding schema for coding a random sample of $10 \%$ of the quotations. We trained the second coder, a final year doctoral candidate in Business Administration, using a pilot test of 17 random quotations (one from each interview). Based on the differences found in the pilot test, we extended the original 33 codes to 41, and we recoded over 100 quotations accordingly. For instance, we broke down the code "accessing resources-material" to the codes "accessing material", "accessing PowerPoints-slides", and "accessing files" based on the exact wording used by the interviewees. We chose 51 random quotations ( 3 from each interview, different from the training sample) for the second coder. We told the coder the number of codes for each quotation, so we could calculate the kappa. The process resulted in a kappa of 0.89 , which is indicative of very high agreement between coders. The two coders discussed and reconciled the differences of the coding of quotations, and this resulted in changes in the coding of 1 of the sampled quotations; moreover, 3 non-sampled quotations were recoded accordingly.

Next, we used axial coding to relate the open codes to each other and to group the related actions and behaviors into functional categories, thus allowing meaningful affordances to emerge. While the open codes arise from and stay close to the data, the axial codes arise from the theory and relate the open codes that refer to a theoretical concept. We gave paid special attention to the fact that affordances a) are functional and thus express students' explained purposes and goals and b) cover the range of behaviors we captured in the interview data. After going through the qualitative coding and analysis process, five main Moodle affordances emerged. Of the seven axial codes we came up with as affordances of Moodle, we decided not to include "Receiving Notification" and "Personalization" for further analysis. Personalization refers to the users' ability to modify their Moodle personal profile, such as changing their photo and personal description that are visible to other users. It includes a single code of "editing personal profile" which occurred in only 1 quotation. While Personalization could be an important affordance of Moodle, it clearly is not well perceived and actualized by the Moodle users in our particular study. Although Receiving Notification appears relatively frequently (in 23 quotations), it is not actually an affordance in the sense of affordances theory [35], in that it does not need any user action to be actualized (other than a single action of initially requesting notifications to be sent, which is not what our interviewees were referring to).

Our identification of the affordances took into consideration students' purposes and motives while using Moodle. After analyzing all the interviews, we revised the definitions of the affordances from those used in the pilot study. The five affordances follow:

- Content Access: Action possibilities enabling the students to access any course content that they need; these possibilities give the students read-only access to the course-related material.

- Submission: Action possibilities enabling the students to submit their work, answers, or ideas for part of their course grade, for which they might or might not receive subsequent feedback.

- Communication: Action possibilities enabling the students to communicate and share their ideas, opinions and questions with the teacher, teaching assistants or fellow classmates; or to acquire awareness of what the teacher, teaching assistants or classmates communicated or shared; both parties have the chance to express themselves and engage in two-way interaction.

- Practice: Action possibilities enabling the students to practice what they have already learned about the course material.

- Feedback: Action possibilities enabling the students to get feedback on their learning, participation, submitted work or status or progress in the course.

\subsection{Step 2: Identifying Actions that Actualize Affordances with Card Sorting}

We used card sorting to understand how user actions actualize the five major affordances identified in the previous step. We extracted a list of 53 different actions from the log data of the 260 students of three sections of the same course that used Moodle 
for a full semester. This course required an extensive use of Moodle and thus covered a wide range of possible student actions.

We conducted two rounds of card sorting with multiple experienced student users (called "judges" in card sorting) in each round. There is no definitive rule for the number of judges to be employed, but it is generally agreed that it should be small and may vary depending on the context and concepts [53]. Following the model of Moore and Benbasat [47], we chose five judges for each round. In the first round, we asked the five judges to sort each of the 53 identified user actions into one of the five identified affordance categories. One of the authors met with each judge individually and explained the procedure and the meaning of each category and action. Then, the judge went through actions on a custom-designed spreadsheet and, considering their personal experiences on Moodle, assigned each action to the most relevant affordance category actualized and fulfilled by that action. For instance, the action defined as "visiting the page to upload files for your assignment" was sorted by everyone into the Submission affordance, and the action defined as "replying to an existing discussion on a forum" was sorted by everyone into the Communication affordance. At the end, the researcher asked questions about the reasoning behind the judges' choices. This helped us understand users' intentions and the purposes behind their actions and to clarify the definitions of the affordances we provided.

The first round of card sorting resulted in inter-rater reliability, Fleiss' kappa, of 0.74 ; a kappa higher than 0.65 can be considered an acceptable level of inter-rater agreement [47], [54]. To improve the agreement, we made three changes to the definitions of the actions and affordances, clarifying that the first page of quizzes we referred to in our dataset were quiz instructions. Additionally, one of the judges raised the fact that the page for all quizzes includes quiz grades if available, so we highlighted that in its definition. The pilot study had already highlighted the fact that visiting the main page of an assignment could actualize different affordances if it occurred before or after the assignment was submitted, so we incorporated this as well.

For the second round, we repeated the procedure of the first round with ten different experienced student users on the revised set of action definitions. Although Moore and Benbasat [47] considered five judges sufficient, we used twice that number to increase the rigor of our analysis. 6 actions received an agreement level of less than $80 \%$ in both rounds, so we removed them to end up with a final list of 47 actions. The process resulted in inter-rater reliability, a kappa of 0.90 , demonstrating very high agreement, and so we needed no further rounds of card sorting.

\subsection{Step 3: Creating Personas by Identifying Patterns of Affordance Actualization with Cluster Analysis}

We collected Moodle log data for 456 students in four sections of an introductory business course taught by a single instructor during the same semester. We deliberately chose this specific course for several reasons. First, it uses Moodle extensively: it posts course content, runs weekly quizzes, uses forums, posts assignments and receives submissions, and reports grades on Moodle. Second, our choice controls for the instructor- and course-related variables that could affect students' use of Moodle, like the teaching style and the way instructors use Moodle. The students in all four sections used exactly the same integrated
Moodle site, as if they belonged to just one section.

We collected the data for the four sections from the Fall 2015 semester. We included only students who did not drop the course, that is, who used Moodle for the whole semester. In all, the dataset recorded over 346,000 actions in Moodle for the 456 students who completed the course.

As a complementary analysis, we also collected and fully analyzed an enlarged dataset of Moodle log data for nineteen sections of two other coordinated courses taught by eight instructors (see the online appendix). In fact, even though those courses featured some variations in how the instructors used Moodle, the results were very similar to those for our primary homogenous dataset. Thus, we report the analysis of our primary dataset in this article, and only a summary of the analysis for the enlarged data in the last paragraph of section 4.4 Results. The detailed results of the analysis on the enlarged dataset of 2,393 students is available in the online appendix.

To prepare the data for processing, we ran hierarchical clustering on the dataset to look for singleton clusters (that is, clusters with only one user); we found no outliers. To retain the variation and the proportional importance of different variables, we did not standardize the data; in fact, standardization is unnecessary for the Pearson correlation measure of distance that we used, as explained later.

To conduct the data analysis, we used $\mathrm{R}$ version 3.2.1, including its base package [55], cluster package [56], ggplot2 package [57], reshape2 package [58] and hyperSpec package [59]. We followed the guidelines provided by Borcard et al. [60] to conduct agglomerative hierarchical cluster analysis and identify groups of users with similar types of behavior. This technique is popular because it visually provides the distance between the groups and their sub-groups in a dendrogram diagram (see Figure 1), so it helps in making an informed decision about the appropriate number of clusters to select. The algorithm starts with one cluster for each data point and then computes the closest clusters and merges them into one cluster. This process of agglomeration continues until it gets to one general cluster including all data points. We employed a clustering method based on betweengroup linkages that computes the average distance between each two members of every two clusters, and then merges the two groups with the smallest average distance.

Furthermore, we made an important distinction when choosing the distance measure that calculates the distance between each two data points (users); we chose a distance measure of Pearson correlation because our goal is to create personas representing major user behaviors. What matters to us is the pattern rather than the level of affordance actualization, because we are interested in how users actualize affordances proportionally and in relation to other affordances. Personas would be more informative to a system design team when they are representative of how users use the system rather than how much they use it; this means focusing on the quality of use rather than on its quantity [61]. Hierarchical clustering based on Pearson correlation distance results in clusters of students with highly correlated affordance actualization measures. In other words, students of each cluster supposedly will follow a similar, correlated manner in how they actualize various affordances. 


\subsection{Results: Affordance-based Moodle User Personas}

Figure 1 is the dendrogram depicting the hierarchical clustering results. In identifying the appropriate number of clusters in a cluster analysis, the goal is to identify a minimal number of clusters with the lowest distance within each group and highest distance across the groups; each cluster must have a meaningful

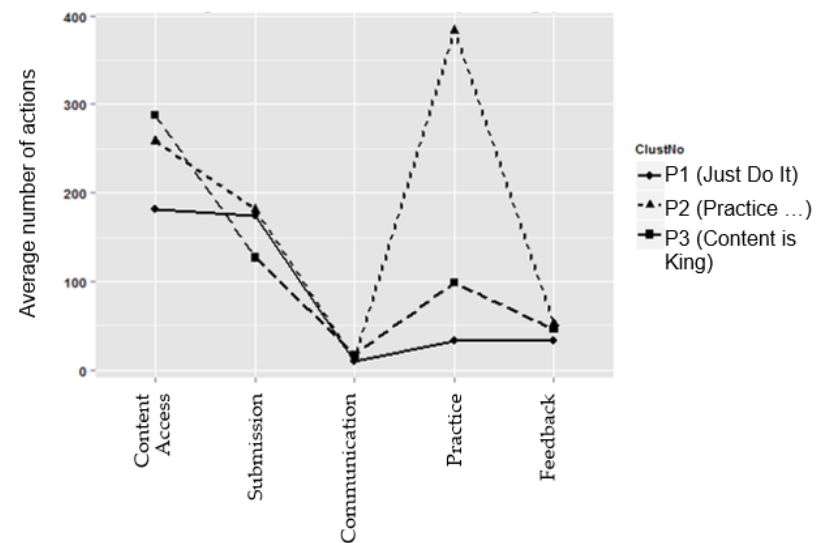

number of members to be considered a group. Concerning the "right" number of clusters to select, Tan et al. [62] assert that "cluster analysis divides data into groups (clusters) that are meaningful, useful, or both" [62, p. 525]. They define meaningful clusters as "classes, or conceptually meaningful groups of objects that share common characteristics, play an important role in how people analyze and describe the world" [62, p. 525]. Therefore, we are looking for meaningful personas that can explain our dataset, rather than generalizable ones that might apply universally.

\section{Figure 1. Dendrogram resulting from Hierarchical Cluster} Analysis

Tan et al. [62] further explain "that the definition of a cluster is imprecise and that the best definition depends on the nature of data and the desired results" [62, p. 526]. Considering the context of this study to create personas that helps in redesigning Moodle, we regard any cluster of smaller than $10 \%$ of the sample to be too small to represent a valuable pattern. Scholars can and should make such a decision on their own based on the realities of their context.

We chose to cut the dendrogram tree at the height of 0.1 because that gives us three major clusters that demonstrate a significant amount of between-group distance, while the distance among members within a cluster is small. Furthermore, each cluster includes at least $10 \%$ of all members with no outliers and with all users clustered into one of the three clusters. Table 4 represents the number of users in each cluster and the average number of affordance actualizations for each cluster. It also reports the results of ANOVA for mean differences in affordance actualizations among the three personas.

Table 4. The cluster population, mean affordance actualization, and ANOVA results

\begin{tabular}{|l|r|r|r|r|r|r|}
\hline & & \multicolumn{5}{|c|}{ Mean Number of Actions Taken to Actualize } \\
Each Affordance \\
\cline { 3 - 7 } Cluster & Popula- \\
tion Size & $\begin{array}{c}\text { Content } \\
\text { Access }\end{array}$ & $\begin{array}{c}\text { Submis- } \\
\text { sion }\end{array}$ & $\begin{array}{c}\text { Com- } \\
\text { muni- } \\
\text { cation }\end{array}$ & Practice & $\begin{array}{c}\text { Feed- } \\
\text { back }\end{array}$ \\
\hline Just Do & $\mathbf{1 5 3}$ & 181.4 & 173.6 & 9.1 & 33.4 & 32.2 \\
\hline
\end{tabular}

\begin{tabular}{|r|r|r|r|r|r|r|}
\hline it (P1) & $\mathbf{( 3 4 \% )}$ & & & & & \\
\hline $\begin{array}{r}\text { Practice } \\
\text { Makes } \\
\text { Perfect } \\
\text { (P2) }\end{array}$ & $\begin{array}{r}\mathbf{2 1 6} \\
\mathbf{( 4 7 \% )}\end{array}$ & 258.3 & 180.8 & 12.7 & 383.5 & 52.6 \\
\hline $\begin{array}{r}\text { Content } \\
\text { is King } \\
\text { (P3) }\end{array}$ & $\begin{array}{r}\mathbf{8 7} \\
\mathbf{( 1 9 \% )}\end{array}$ & 287.2 & 126.9 & 17.3 & 98.2 & 46.4 \\
\hline $\mathbf{A l l}$ & $\begin{array}{r}\mathbf{4 5 6} \\
\mathbf{( 1 0 0 \% )}\end{array}$ & 238.0 & 168.1 & 12.4 & 211.6 & 44.6 \\
\hline $\begin{array}{l}\text { F (and p-value) } \\
\text { for ANOVA mean } \\
\text { differences }\end{array}$ & $\begin{array}{l}47.04 \\
(.000)\end{array}$ & $\begin{array}{l}30.03 \\
(.000)\end{array}$ & $\begin{array}{l}12.80 \\
(.000)\end{array}$ & $\begin{array}{l}328.53 \\
(.000)\end{array}$ & $\begin{array}{l}29.99 \\
(.000)\end{array}$ \\
\hline
\end{tabular}

Figure 2 and Figure 3 represent the average number of actual and standardized affordance actualizations in each of the three clusters, respectively. While Figure 2 keeps the original scale to highlight the differences in the frequency of actualizations between the five affordances, Figure 3 standardizes the scale to focus on the differences between the three personas for each affordance.

Figure 2. Average number of affordance actualizations across personas

Persona 1, characterized as "Just Do It", comprises $34 \%$ of the sample. Users in this cluster mostly actualize Moodle affordances at the minimum levels; they just do what is required to fulfill course duties. They actualize all affordances except for Submission at significantly lower levels than other clusters.

Persona 2, characterized as "Practice Makes Perfect", comprises $47 \%$ of the sample. Their use of Moodle is highly focused

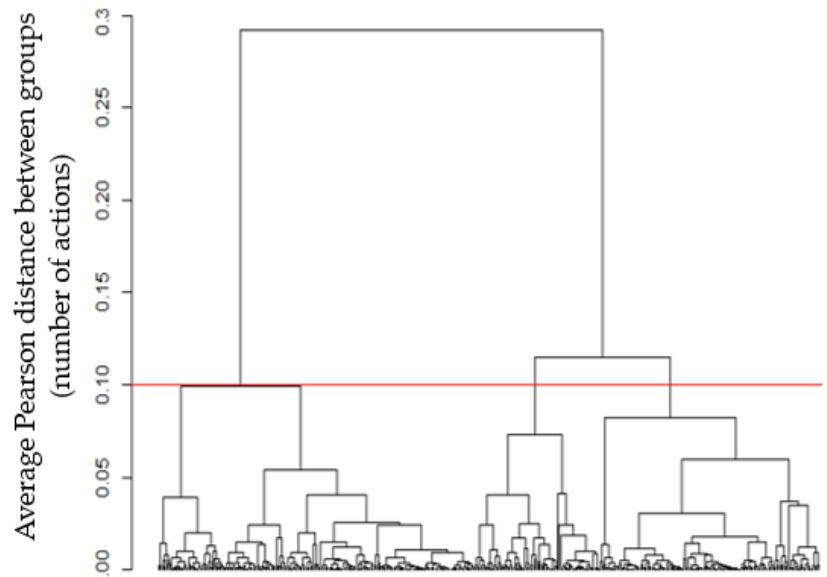

on actualizing the Practice affordance and somewhat oriented towards the Feedback affordance. Although they actualize the Content Access affordance at a high level, they are not the persona that actualizes Content Access the most.

Persona 3, characterized as "Content is King", comprises $19 \%$ of the users in the sample. The use of Moodle in this cluster is more highly focused on actualizing the Content Access affordance than in the other clusters. Although the users meaningfully actualize the Practice and Feedback affordances of Moodle, these seem to be secondary to their Moodle usage.

The ANOVA results reject the hypotheses for mean equality among the three personas for each of the five affordances (see 
Table 4). That is, for each respective affordance, some of the personas actualize the affordance at significantly different levels. The Tukey HSD test results demonstrate that the three personas are meaningfully differentiated on the five affordances ( $p$-value of mean differences < 0.002), except in only two cases: Just Do It and Practice Makes Perfect personas are not differentiated in their Submission affordance actualization $(\mathrm{p}=0.439)$; and Practice Makes Perfect and Content is King personas are not differentiated by their Feedback affordance actualization $(p=0.130)$.

We found that the Practice affordance is the one that differentiates the three personas the best. That is, while the Just Do It persona tends to actualize the Practice affordance around 50 times and less during the semester, the Practice Makes Perfect persona tends to actualize the affordance in a range of 200 to 600 actions during the semester. In addition, the Submission affordance does not really differentiate the Just Do It and Practice Makes Perfect personas.

\section{Figure 3. Average standardized number of affordance} actualizations across personas

Similarly, the Feedback affordance is unable to differentiate the Practice Makes Perfect and Content is King personas; that is, the two personas are somewhat similar in their actualization of the Feedback affordance.

We also analyzed an enlarged dataset including another nineteen sections of two other courses taught by eight instructors. It comprised 2,393 students who used the system for a full semester. We did not include this larger dataset in our main analysis in this article because of certain differences in how they used Moodle, like the number of practice and graded quizzes available, the number of questions per quiz, the number of assignments provided, and the number of voluntary and mandatory forums available. Interestingly, the analysis resulted in three mostly similar personas. One persona actualizes Practice affordance at the highest level and relies heavily on Feedback and Submission (i.e. Practice Makes Perfect). Another persona actualizes Content Access more than others and relies on other affordances moderately (i.e. Content Is King). The third persona actualizes all affordances at the lowest level compared to the other two personas (i.e. Just Do It). The three personas capture $77 \%$ of the larger sample. However, Content Is King behaves a little differently in the larger sample because it actualizes Submission and Communication at moderate levels compared to the two other personas. Additionally, in terms of their proportional size in the larger dataset, Just Do It represents the largest persona and then Practice Makes Perfect and Content is King. In contrast, in the focused dataset analyzed in this article, Practice Makes Perfect is the largest followed by Just Do It and then Content Is King. The results of the analysis on the enlarged dataset are available in the online appendix.

Next, we turn to creating qualitative-only personas and presenting independently-developed qualitative-only personas so that we can compare such personas with the affordance-based ones we developed here.

\section{Comparative Development of Personas}

\section{USING EXISTING APPROACHES}

One of the primary contentions of this study is that the affordance-based personas that we describe benefit from the advantages of those developed using existing quantitative- and qualitative-only methods and offer further numerous benefits (see Table 2). To illustrate the value of affordance-based personas compared to either quantitative or qualitative personas, we used our collected data to create and analyze alternative personas using best practices from the classical approaches. We used the Moodle log data to create quantitative personas using Principal Component Analysis (PCA), which is arguably the most credible quantitative persona creation technique [5]. Moreover, we drew on previously designed Moodle user personas created using three case studies [63] to compare personas developed by only qualitative methods. In the following, we report our empirical data collection and analysis, the affordance-based personas, the quantitative personas, and the pre-built qualitative personas. In the

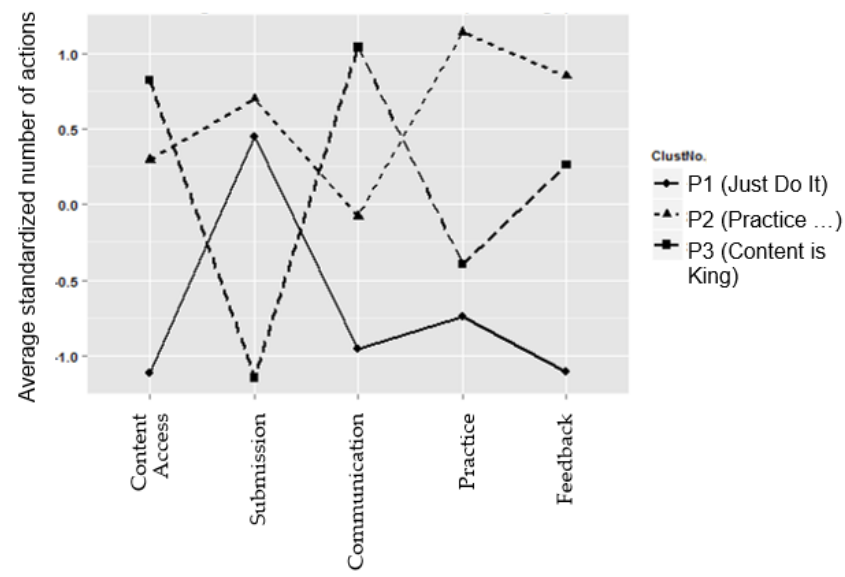

discussion section of this article, we will compare these three types of personas and assess the insights obtained from our proposed affordance-based mixed-methods approach.

\subsection{Quantitative Moodle User Personas}

Among the various quantitative techniques for creating user personas, Principal Component Analysis (PCA) has been demonstrated to be the most credible technique [5]. PCA is a dimension reduction technique that finds the few components that can account for most of the variance in observations of many variables. We followed the steps provided by Sinha [31] and Brickey et al. [5] to use PCA to analyze the Moodle log data of the 456 users of our sample.

We conducted PCA with varimax rotation using SPSS 20. We chose three as the minimum number of components that accounts for a meaningful amount of variation among the 31 user actions in the dataset. (The quantitative-only analysis has only 31 actions in the raw log data versus 47 for our proposed methodology because it does not benefit from the qualitative insights that enabled us to fine-tune the differences between many log data actions.) The three components accounted for $20 \%, 13 \%$, and $9 \%$ of the variance, respectively. Examining the rotated component matrix and the actions that significantly load on each component with loading of over 0.7 , we came up with the following three quantitative personas:

1. PC1, characterized as "Quizzer", heavily uses quiz-re- 
lated features by starting, doing and submitting quizzes, reviewing quiz responses, and checking the summary of their quiz attempts.

2. PC2, characterized as "Time Manager", uses calendar and scheduler features by creating and updating calendar events, and adding, checking, or removing booking schedules. They use the Moodle calendar to remind themselves of specific deadlines and events. Also, they use the scheduler to make appointments with the instructor or TA for meetings.

3. PC3, characterized as "Forumer", frequently checks the main pages of forums and the discussion pages for various forums. They also tend to check the list of users and their profile pages. Moreover, they tend to check their grades.

Next, we consider three pre-built qualitative personas and how our dataset may support them.

\subsection{Qualitative Moodle User Personas}

Because of their contextual richness, qualitative techniques are the most popular for creating personas [5]. However, it is beyond the scope of this study to engage in the lengthy process of creating new alternate personas based solely on qualitative data. To be able to compare and contrast affordance-based personas with their qualitative counterparts, we draw on existing research that has developed such personas for Moodle users. Specifically, we refer to the three Moodle user personas built through three qualitative case studies by Operandi [63]. The three personas are as follows:

1. "Miss Dependent" is very much dependent on the teacher for what she needs to learn; she focuses on the facts introduced to her in the course, rather than on their applications and implications. She is comfortable with procedural learning and practices answering short-answer questions. She values the instructor's feedback on her progress and does not like the stress of quizzes. She is representative of 3 students interviewed by Operandi [63].

2. "Mr. Cue-Conscious" needs to know the criteria on which he is going to be assessed in the course. He cares more about his grade than about his learning. He is not interested in exchanging feedback with other students. He does not discuss assessments with peers but feels OK to criticize peers' work anonymously if he can. He is representative of 5 students interviewed.

3. "Mr. Personal Journey" values his personal interests and takes responsibility for following and learning them. He values his peers and their ideas and thinks their exchanges can be beneficial to both. To him, learning is not only about extending his knowledge, but also about changing his personality, habits and learning capacity. He is representative of 4 students interviewed.

To demonstrate the credibility of the three aforementioned personas in the context of our sample of Moodle users, we analyzed the data from the 17 interviews that we conducted to verify if Operandi's three personas could represent the students in our sample. We extracted relevant quotations that could support characterizing our interviewed students according to Operandi's personas, and we indeed confirmed that his classification based solely on qualitative data could reasonably characterize the students we interviewed. Thus, we can legitimately use Operandi's personas as a representation of what a purely qualitative persona development methodology could produce when applied to our particular data. In the following section, in addition to discussing our results in general, we specifically compare the advantages and disadvantages of the three types of personas.

\section{Comparison of Personas Drawn From Different METHOdS}

In this study, we discuss various methods for creating user personas and suggest a new mixed-methods approach for creating personas based on users' actualization of technology affordances. To illustrate the applicability and value of this new approach, we first collected and analyzed data to create Moodle user personas using the affordance-based approach that we present. Then, to illustrate the relative value of this new approach, we also used best practices to create personas based on only quantitative analysis of our dataset, and we also analyzed our interview data from the perspective of three independently-developed Moodle user personas using only qualitative analysis. Table 5 summarizes the three types of Moodle personas. In addition to our own assessments of the relative value of each methodology for creating personas, we conducted applicability checks [64] to verify the assessments of qualified professionals of the three methodologies and their respective resulting personas. In this section, we describe the results of these applicability checks and then, partially based on the experts' assessments, we critically compare the results of our comparisons.

Table 5. Three types of Moodle personas

\begin{tabular}{|c|c|c|}
\hline Affordance-Based & $\begin{array}{c}\text { Quantitative- } \\
\text { Only }\end{array}$ & Qualitative-Only \\
\hline $\begin{array}{l}\text { •Just Do It: actual- } \\
\text { izes affordances at } \\
\text { minimal levels to } \\
\text { just do what is re- } \\
\text { quired for course } \\
\text {-Practice Makes } \\
\text { Perfect: primarily } \\
\text { focused on Prac- } \\
\text { tice and somewhat } \\
\text { on Feedback; actu- } \\
\text { alizes Content at } \\
\text { high levels but not } \\
\text { the most } \\
\text { - Content is King: } \\
\text { primarily focused } \\
\text { on Content; actual- } \\
\text { izes Practice and } \\
\text { Feedback at some- } \\
\text { what high levels, } \\
\text { but not as the main } \\
\text { focus }\end{array}$ & $\begin{array}{l}\text {-Quizzer: heav- } \\
\text { ily uses quiz-re- } \\
\text { lated features } \\
\text { - Time Man- } \\
\text { ager: uses cal- } \\
\text { endar and } \\
\text { scheduler fea- } \\
\text { tures } \\
\text { - Forumer: fre- } \\
\text { quently checks } \\
\text { forum pages, } \\
\text { grades, as well } \\
\text { as profile pages } \\
\text { of others }\end{array}$ & $\begin{array}{l}\text { Miss Dependent: } \\
\text { highly dependent } \\
\text { on teacher; prefers } \\
\text { procedural learn- } \\
\text { ing and close feed- } \\
\text { back } \\
\text { - Mr. Cue-Con- } \\
\text { scious: cares more } \\
\text { about grade than } \\
\text { about learning, so } \\
\text { very focused on } \\
\text { cues about what } \\
\text { they need to do } \\
\text {-Mr. Personal } \\
\text { Journey: takes re- } \\
\text { sponsibility for } \\
\text { creating their own } \\
\text { learning experi- } \\
\text { ence; interacts } \\
\text { with and learns } \\
\text { from others }\end{array}$ \\
\hline
\end{tabular}

\subsection{Practitioner Assessments of the Methodologies and Their Resulting Personas}

In accordance with Rosemann and Vessey's [64] guidelines for applicability checks, we consulted seven relevant Moodle experts to obtain their assessments of the three methodologies that 
we used for developing personas in this study and the resulting personas: quantitative-based, qualitative-based and affordancebased. Some of these experts were technical implementers or developers of Moodle, some were instructional technology counsellors who specialized in the pedagogical aspects of using Moodle, and some were a mix of both. All combined, they actively worked with Moodle installations in almost 50 different universities or colleges in the same province where we conducted the study. They had an average of 7.8 years of experience with Moodle and an average of 13.3 years of experience with instructional technology in general. We provided the practitioners with documents of three to four pages explaining in detail the concept of "persona", methodologies for developing personas (including ours), and brief paragraphs describing each persona we mentioned in the manuscript. We then asked for their comments, critiques and insights. In Table 6, we highlight selected quotations in response to some of our questions that illustrate the overall assessment of the experts, which we now summarize.

Overall, the experts found the affordance-based personas the most helpful, the qualitative-based personas next, and the quantitative-based personas the least helpful of the three. 
Table 6. Selected quotations from practitioner applicability check

\begin{tabular}{|c|c|}
\hline Question & Selected quotations \\
\hline $\begin{array}{l}\text { Which methodologies } \\
\text { do you think are bet- } \\
\text { ter, and why? }\end{array}$ & $\begin{array}{l}\text { - Pedagogical Counsellor in ICT Integration, University: } \\
\text { o A combination of server-side log analysis and structured interviews would be best. Following } \\
\text { user paths and interactions with the system can provide some insights, but not enough data on } \\
\text { its own to assess user needs. } \\
\text { - Coordinator of Educational Technology, College: } \\
\text { O Using the Quantitative Approach will allow you to analyze a bigger amount of data.... The } \\
\text { Qualitative Approach will demand more time to collect the data and also to analyze them. As } \\
\text { the number of people to be interviewed is not big (10 - 20), the results may not be conclusive. } \\
\text { The Affordances Approach seems to be a mix of both (Quantitative and Qualitative). }\end{array}$ \\
\hline $\begin{array}{l}\text { How credible do the } \\
\text { three methodologies } \\
\text { seem to you as good } \\
\text { ways for creating } \\
\text { meaningful per- } \\
\text { sonas? Please com- } \\
\text { pare them if you can. }\end{array}$ & $\begin{array}{l}\text { - IT Instructor and Training Content Developer, University: } \\
\text { o I think that the Affordance approach might give a more in-depth view of different personas ... } \\
\text { - Coordinator, LMS Platform Support for Group of } 40 \text { Colleges: } \\
\text { o I personally have a hard time with automated data collection without considering the actual per- } \\
\text { sons behind. Education and student behavior are more complex than e-commerce. I understand } \\
\text { now why the quantitative approach didn't really make sense .... You cannot seriously claim to } \\
\text { understand what is going on only with digital data. }\end{array}$ \\
\hline $\begin{array}{l}\text { How credible do the } \\
\text { three sets of personas } \\
\text { seem to you in de- } \\
\text { scribing Moodle stu- } \\
\text { dent users? Please } \\
\text { compare the three } \\
\text { sets of personas if } \\
\text { you can. }\end{array}$ & $\begin{array}{l}\text { - Computer Analyst, University: } \\
\text { - The three sets seem credible, but I wonder if there's many users [that] can be represented by } \\
\text { only using one activity type, like "Quizzer" or "Forumer". } \\
\text { - LMS Technical Lead, University Health Centre: } \\
\text { ○ Quantitative Set: I think this set of personas is the least credible, because the results will be } \\
\text { skewed based on the content that is available and the requirements of the course. ... The result- } \\
\text { ing personas seem shallow or superficial. } \\
\text { o Affordances Set: I'll call this set of personas credible not because of the methodology (which I } \\
\text { had a tough time wrapping my head around), but because of the results, which seem to be the } \\
\text { more useful of all the sets of personas. This set gives a look at the mindset of the different types } \\
\text { of personas which would explain how students use Moodle the way they do. }\end{array}$ \\
\hline $\begin{array}{l}\text { How informative and } \\
\text { insightful do you } \\
\text { think the three sets } \\
\text { of personas are for } \\
\text { you or for other pro- } \\
\text { fessionals who work } \\
\text { with Moodle? Please } \\
\text { compare the three } \\
\text { sets of personas if } \\
\text { you can. }\end{array}$ & $\begin{array}{l}\text { - LMS Technical Lead, University Health Centre } \\
\text { o Quantitative Set: Informative in telling us what users did, but no real insight as to why the users } \\
\text { do what they do. } \\
\text { o Qualitative Set: This set was almost the opposite end of the spectrum from the quantitative } \\
\text { set-delving too deep into the mindset of users. The set doesn't really explain why one persona } \\
\text { would use certain Moodle features over others. It seems like these personas are more focused } \\
\text { on students' attitudes toward the class and learning itself as opposed to Moodle. The set might } \\
\text { be useful and insightful to a psychologist but not to anyone else. } \\
\text { O Affordances Set: I found this set the most informative and insightful. It gives a glimpse into the } \\
\text { students' mindset while at the same time explaining why one persona would favour certain } \\
\text { Moodle features over another persona. } \\
\text { - Coordinator, LMS Platform Support for Group of } 40 \text { Colleges: } \\
\text { o Because of the "just do it" persona, I prefer the Affordances Set. To me, it is very important to } \\
\text { keep in mind that some students will never get involved in online collaboration and will only } \\
\text { work to pass the course. The personas in the qualitative set do not seem to consider that type of } \\
\text { student, for whom logging in to Moodle is a painful experience and who want to get rid of the } \\
\text { job as fast as possible. The "Mr. Cue-Conscious" label sounds maybe too positive. }\end{array}$ \\
\hline $\begin{array}{l}\text { How representative } \\
\text { do you think the } \\
\text { three sets of personas } \\
\text { are of actual Moodle } \\
\text { users? Please com- } \\
\text { pare the three sets of } \\
\text { personas if you can. }\end{array}$ & $\begin{array}{l}\text { - LMS Technical Lead, University Health Centre: } \\
\text { o Quantitative Set: I don't think this set is terribly representative of Moodle users, because this set } \\
\text { depends on what is on the Moodle platform. (Disable forums, and suddenly the "forumer" per- } \\
\text { sona disappears, and you're left with something else.) } \\
\text { o Qualitative Set: This set seems representative of students, but not necessarily of Moodle users. } \\
\text { For example, all three personas in this set might have the same "just do it" persona when it } \\
\text { comes to using Moodle. } \\
\text { - Affordances Set: I find this set very representative of Moodle users. } \\
\text { - Coordinator, LMS Platform Support for Group of } 40 \text { Colleges: } \\
\text { o Again, I would choose the affordances set at my level.... In the qualitative set, I find "Mr. Per- } \\
\text { sonal Journey" almost too good to be true. It sounds too much like the perfect online learner, } \\
\text { one that will succeed in any course design. }\end{array}$ \\
\hline
\end{tabular}


Concerning the quantitative set of personas, experts generally considered the methodology meaningful because of its data-analytic approach based on the full set of users (e.g., "Using a big database with the aid of scripts and learning analytics to extract and analyze information seems the best way"). However, they found its resulting personas rather shallow (e.g., "I think this set of personas is the least credible, because the results will be skewed based on the content that is available and the requirements of the course"). Concerning the qualitative set of personas, experts were more mixed concerning the methodology, as some liked the in-depth interviews (e.g., "I personally have a hard time with automated data collection without considering the actual persons behind") whereas others disliked the narrow solicitation of the input of only a small selection of users (e.g., "As the number of people to be interviewed is not big $(10-20)$, the results may not be conclusive"). They found the resulting personas more helpful than the quantitative set, but they were not very satisfying (e.g., "delving too deep into the mindset of users. The set doesn't really explain why one persona would use certain Moodle features over others").

The experts generally found the affordances-based approach superior to the quantitative-only and qualitative-only approaches, largely because its methodology explicitly combines the best of the two others (e.g., "A combination of server-side log analysis and structured interviews would be best"). However, and more importantly, they considered the resulting personas more informative, insightful, and representative of Moodle student users. For example, "It gives a glimpse into the students' mindset while at the same time explaining why one persona would favor certain Moodle features over another persona", and, "Because of the "just do it" persona, I prefer the Affordances Set. To me, it is very important to keep in mind that some students will never get involved in online collaboration and will only work to pass the course." In Table 6, we list some of the main questions we asked the experts and select some quotations that illustrate our overall assessment here. In the following subsection, we critique in more detail in what ways our affordancebased approach to developing personas improves the existing approaches.

\subsection{Advantages of Affordance-Based Mixed- Method Personas}

Comparing these three approaches to developing personas (our new affordance-based approach, a quantitative-only approach and a qualitative-only approach) provides multiple insights on the advantages of affordance-based personas that address the shortcomings of the other approaches depicted in Table 2.

First, our affordance-based personas are grounded in and representative of the data from a large sample of users. This is the primary advantage of quantitative-only personas over qualitative-only ones. The grounding in a large body of users makes it easy to communicate such personas to system development teams because they can be supported by objective user data. For instance, the affordance-based Just Do It, Practice Makes Perfect and Content is King personas represent respectively 34\%, $47 \%$ and $19 \%$ of 456 sample users $(100 \%)$. Similarly, quantitativeonly Quizzer, Time Manager and Forumer personas capture all 456 users of our sample. In contrast, the qualitative-only Miss Dependent, Mr. Cue-Conscious, and Mr. Personal Journey are created on a base of only 3, 5 and 4 students, respectively, whom the researcher interviewed; it is not clear if they are representative of a larger Moodle user community. In addition, the relative size of the personas provided by the affordance-based approach can be indicative of the relative importance of those personas to system design teams. For instance, the $47 \%$ size of the Practice Makes Perfect persona may prioritize it over the $19 \%$ size of the Content is King persona when it comes to making design decisions.

Second, like quantitative-only personas, our affordance-based personas are created using a method that is not overly dependent on the experience and cognitive capabilities of the personas' designer. For instance, the qualitative personas are built completely based on user interviews that require particular qualitative analysis skills to conduct and interpret them. In contrast, our affordance-based personas are built using interview, card sorting, and $\log$ data analysis in which the persona designers' qualitative analysis skills play a considerably smaller role. On the one hand, analysts indeed need qualitative skills for identifying affordances from interview data, which is more demanding than with quantitative-only personas. On the other hand, this cognitive task is much simpler than that required to create complete personas from the data, as in the case of qualitative-only personas. In all, the proposed method requires fewer cognitive capabilities and less experience from the persona designers.

Third, our affordance-based personas, unlike quantitativeonly approaches, provide the context about the personas over and above merely describing the actions that the users take. These personas entail the meaning and purpose of the actions taken and provide an understanding of the objectives that the actions serve. For instance, whereas the quantitative personas of Forumer and Time Manager refer mostly to a number of related and unrelated actions that comprise the respective personas, they do not involve the users' purpose and reason for taking those actions. They do not even explain how those actions relate to each other. Thus, the persona designer has to consider the meaning and intention behind those actions and how they are related. In fact, sometimes it may be impossible to find a plausible rational justification for why certain actions are used by the same persona. For example, it is not clear how and why Forumers would check their grades and what the purpose of such behavior would be. However, the affordance-based method takes care of this issue by using card sorting to find the relation between actions and the affordances they actualize. If the assignment of actions to affordances is not clear, then the user judges can explain to the persona designers the logic and provide the context for their actions. We note that although qualitative-only personas are much more likely than quantitative-only ones to incorporate the purposes of actions, they do not link those purposes to user actions as explicitly as the affordance-based approach we describe.

Fourth, the affordance-based personas are less about who the users are and more about how and why they use and interact with the system and for what purpose. This results in personas that are more readily usable and insightful in making the design decisions. For instance, it would not be easy to make insightful design decisions that support Miss Dependent, Mr. Cue-Conscious and Mr. Personal Journey in their Moodle use because we do not understand very well how their focus on facts, grades or personal learning, respectively, affects their use of Moodle. However, af- 
fordance-based personas provide readily usable insights for system design teams. For instance, the Just Do It persona may need all the affordances in a single place rather than fully featured affordances put in different places; a dashboard with all updates and relevant links to the active quizzes and assignments might serve the Just Do It persona well.

Fifth, the affordance-based personas provide the behavioral patterns of the personas rather than merely presenting a few behavioral or demographic variables. This gives further insight for design decisions. For instance, the Quizzer quantitative-based persona identifies a list of the quiz-related actions that should be supported by the designers, but this does not provide much guidance as to what exactly this persona needs. However, the development of the Practice Makes Perfect affordance-based persona reveals heavy dependence on quiz-related actions as well as on feedback-related ones. So, the designers could readily understand that they need to incorporate more feedback in practicerelated features. Whereas the quantitative-based personas highlight specific actions, the affordance-based personas place those actions in context and interrelation to each other, which can readily guide sensible design decisions.

Sixth, the affordance-based personas address the limitations of the current mixed-methods approaches (see Table 7). The existing mixed-methods approaches use quantitative-only methods to group users into clusters or personas, and then use qualitative data from those users to provide context and enrich the personas. As such, they do not use the qualitative insights to identify the personas, but only to enrich them after they have been identified. However, the affordance-based personas we describe are identified by analyzing quantitative data at the level of qualitative af fordances. For instance, the Just Do It persona is identified by its minimal actualization of four out of five qualitative affordances. The proposed combination of quantitative and qualitative insights leverages the full potential of the mixed-methods approach and provides rich and representative personas. Table 7 summarizes the limitations of the current persona creation techniques and how our proposed affordance-based method addresses them.

While this study demonstrates the applicability, richness, and representativeness of affordance-based personas, there might be a concern about how generalizable and usable the personas are if they are built on homogenous sample users of a certain implementation of a system, like Moodle in this case. Although affordance-based and quantitative personas prove to be more generalizable than qualitative ones, they have not been able to address the generalizability concern in full. While we do not expect universal personas of customizable systems like Moodle to exist independently of the specific system configuration in use, persona designers need to be specific about the boundaries of generalizability of the created personas. For that purpose, we repeated our persona creation with the same interview and card sorting data, but using an enlarged and more diverse Moodle log dataset comprising a total of 2,393 students from 23 sections of three courses in the same business school, including the course of 4 sections with 456 students that we analyzed here. The results are summarized in the last paragraph of section 4.4 Results (see the online appendix for full analysis). Comparing the results, it is safe to say that the same three affordance-based personas are representative of Moodle users in the larger, more heterogeneous dataset as long as the specific system configuration provides the same basic features, for example, content (text and files), practice (quizzes) and feedback (grades).

Table 7. The limitations of current persona creation techniques addressed by the proposed affordance-based method

\begin{tabular}{|l|l|l|}
\hline $\begin{array}{l}\text { Disadvantages } \\
\text { Limitations) }\end{array}$ & Method & \multicolumn{1}{|c|}{$\begin{array}{c}\text { How Addressed by Our Af- } \\
\text { fordance-Based Method }\end{array}$} \\
\hline $\begin{array}{l}\text { Lack of con- } \\
\text { textual rich- } \\
\text { ness }\end{array}$ & Quantitative & $\begin{array}{l}\text { The actions are examined in the } \\
\text { context of affordances, so the per- } \\
\text { sonas are not about the actions us- } \\
\text { ers take but the purpose they pur- } \\
\text { sue. }\end{array}$ \\
\hline $\begin{array}{l}\text { Potential lack } \\
\text { of credibility } \\
\text { and rigor }\end{array}$ & Qualitative & $\begin{array}{l}\text { The patterns are credible and rep- } \\
\text { resentative of a large group of us- } \\
\text { ers; use of card sorting and clus- } \\
\text { tering in combination with quali- } \\
\text { tative analysis enhances rigor. }\end{array}$ \\
\hline $\begin{array}{l}\text { Takes very } \\
\text { much time } \\
\text { and many re- } \\
\text { sources to de- } \\
\text { velop }\end{array}$ & Qualitative & $\begin{array}{l}\text { Just relatively few user interviews } \\
\text { reveal the affordances. }\end{array}$ \\
\hline $\begin{array}{l}\text { Groups are } \\
\text { made based } \\
\text { solely on } \\
\text { quantitative } \\
\text { data }\end{array}$ & $\begin{array}{l}\text { Current mixed } \\
\text { quantitative } \\
\text { and qualitative } \\
\text { approaches }\end{array}$ & $\begin{array}{l}\text { Personas are created based on af- } \\
\text { fordance actualization patterns } \\
\text { which are identified using both } \\
\text { quantitative log data and qualita- } \\
\text { tive interview insights. }\end{array}$ \\
\hline
\end{tabular}

However, with the larger dataset, considering the patterns and the size of Moodle use, three of the five affordances available to Moodle users appear to be more important in shaping user experience and personas: Content Access, Practice, and Feedback. These were actualized at very high levels and successfully differentiate the three personas, except for Feedback which only marginally differentiates the Content is King and Practice Makes Perfect personas; this may be indicative of less different use of Feedback by those two personas compared to its distinctly lower use by Just Do It users. The Submission affordance, although partially differentiating the three personas, was mandated by the instructors for part of the course grade. Therefore, its actualization was mostly regulated by the instructors, and it would not be reflective of student preferences. Although the Communication affordance differentiates the three personas, it was actualized at very low levels in general, with an average of 12.8 actions throughout the semester. This finding is consistent with the qualitative evidence from students that they would rather use Facebook and other social media for course-related communications with each other than use Moodle.

\section{Discussion}

\subsection{Implications}

The proposed affordance-based approach to user persona creation has important implications for research and practice. For persona research, it highlights the need for and feasibility of new approaches that provide contextually rich and more representative personas. This affordance-based approach is a viable alternative that can cover most of the limitations of the existing approaches. It suggests affordance actualization as a new and fruitful unit of analysis for user behavior research. Affordances entail the meaning and purpose of user actions, so they provide the context in which the actions should be understood. For IS research, the suggested technique provides new analytical tools to quantify affordance actualizations and analyze user behavior in terms of the patterns of user actualization of affordances rather than 
merely in terms of the actions they take. Over and beyond these implications, this study highlights the potential of the affordance theory for bridging the design-oriented persona research and the behavioral IS research. It demonstrates how design research can benefit from more behavioral approaches to examine and analyze patterns in user behavior.

For persona designers in general, this study provides detailed tools and techniques to create personas using a combination of qualitative data collection and quantitative user log data. It is practical because it can be conducted with just a few interviews, a few rounds of card sorting, and readily available user log data. It provides persona designers with practical insights on user behavior patterns and on how to improve the system to support those patterns.

For designers and instructors of the Moodle community specifically, this study highlights three major personas with distinct patterns of Moodle use in a context of rich use of Moodle features. Just Do It users may be supported by having a dashboard that provides them with the access to updates, assignments, forums and quizzes that they need to attend to at any given time. They appreciate receiving announcements or notifications about updates and changes on the site. At the same time, they would be bothered if they received too many notifications, for instance for forum posts, that they do not care about.

Practice Makes Perfect users appreciate any opportunity to practice their knowledge and also like to know how they are performing on those practice exercises and in the course in general. They could be supported by incorporating rich feedback into quiz features and other submission capabilities. Instructors and Moodle system administrators should also offer a larger variety of question types in the quiz feature; students would appreciate being able to draw diagrams or manipulate data to answer a question, and so supporting more interactive types of questions would be valuable. (In the instance we studied, the quizzes were mainly textual multiple-choice questions with little variation.) Instructors could support this persona by providing further quizzes and make sure that they give students the correct answers after they finish each question or after the quiz; students would appreciate more explanation on the correct option.

Content is King users are primarily concerned with accessing and using content and material related to the course. They can be supported by giving them easy access to a variety of content types. They like being able to open a file (i.e. Word, PDF, or PowerPoint) in their browser without downloading it. They also like having access to a greater variety of content, such as playing a video directly from Moodle rather on a second page. In addition, they want notifications whenever new content is added.

Practitioners contacted in this study generally found the affordance-based personas more useful and informative compared to the other quantitative- and qualitative-only personas. They found the quantitative personas rather shallow not providing context of the actions and why people take them. While they somewhat like the qualitative personas compared to the quantitative ones, they find the qualitative personas inconclusive because of the small number of users interviewed. They favor the affordance-based methodology for persona creation over and above the others because it clearly brings together the insights from quantitative and qualitative data.

\subsection{Limitations}

There are some limitations of this study that we must note. First, although the affordance-based personas are not only built on qualitative data analysis, they nonetheless depend on qualitatively-derived technology affordances; so, the persona designers will still need some experience and cognitive capacity in analyzing qualitative data. Since the user log data will be analyzed based on the affordances identified, it is essential to identify the major and significant affordances of the technology. However, the card sorting exercise greatly helps to properly modify and improve the identified affordances. For instance, if any major affordance is missing, then some frequent actions might not be properly sorted into the available affordances.

Second, the required types of data for this methodology may limit its applicability in certain contexts. For example, it might be difficult to apply this methodology for creating personas for new technologies that have not existed or been implemented before, as well as for technologies that do not record usage log data. However, it is important to note that, as explained in the introduction, most systems in use in corporate business and governmental agencies are legacy systems for which new development and maintenance is carried out. Thus, most software applications are updates of older ones. However, it is important to note that in the case of new software, data could be gathered from other similar applications. Thus, in the latter scenario, the affordancebased personas we have presented here are still relevant.

The third limitation is related to the previous one: our methodology is only applicable when user log data is readily available. Even when such log data exists, privacy concerns might restrict its availability for analysis. However, most analysts with the responsibility for developing personas would have full authorized access to the necessary user log data. When such user $\log$ data is difficult to access for privacy reasons, analysts could use anonymized data with no change to our methodology. (Indeed, we conducted the research in this article entirely on anonymized data in accordance with the research ethics protocol that we followed.)

Fourth, the generalizability of the personas created should always be considered with respect to the specific implementation of the system studied. As is the case with all persona design, there is no such thing as a universally applicable persona independent of the specific system implementation and organizational context. However, this is a well-known tradeoff between contextualization and generalization in research and as such, the affordance-based personas provide great contextualization which is of paramount importance for software development. This great contextualization then holds promise for making specific and precise recommendations for the development and update of specific software applications.

\section{CONCLUSION}

This study reviews the current approaches to persona creation in user-centered design of technology and highlights the advantages and disadvantages of each. While the more popular qualitative approaches provide contextually rich personas, they are built on few users and are not very representative of the general user community. In contrast, quantitative personas are built on demographic or log data from a larger user sample, but they 
lack the contextual richness needed to understand what the personas represent. Existing mixed-methods approaches create user personas quantitatively based on large samples of users and then enrich the personas with further contextual information acquired qualitatively. However, in doing so, they do not use the qualitative insights during the phase of identifying the personas but only retrospectively to enrich the identified personas.

To address the limitations of the current approaches to persona creation, this article proposes a mixed-methods approach to group users according to their patterns of affordance actualizations. Affordances, the action possibilities provided by a system that guide user behavior, entail the purpose or objectives the actions serve, and therefore put user actions in the richer context of users' purposes. The proposed approach qualitatively identifies the technology affordances, then uses card sorting to identify the user actions that actualize those affordances. Then, it analyzes large sets of user log data at the levels of the affordances they actualize rather than at the level of actions, as do the existing quantitative approaches. It clusters users to produce the personas that actualize affordances with distinct patterns.

To illustrate the applicability and value of the proposed method, we empirically created Moodle user personas in the context of a Canadian business school. The affordance-based approach resulted in three Moodle user personas: Just Do It, Practice Makes Perfect, and Content is King. We used PCA to analyze the same user log data and build quantitative-only personas. We also drew on independently developed qualitative-only Moodle user personas [63] to be able to compare and contrast the advantages of our affordance-based method.

The affordance-based personas have some significant advantages over those of the existing approaches. First, they are grounded in and representative of the data from a large sample of users, unlike qualitative-only personas. Second, their development does not require the intense qualitative skills of qualitativeonly personas. Third, they provide the context about the personas over and above the actions they take, unlike quantitative-only personas. Fourth, they are less about who the users are and more about how and why they use and interact with the system and for what purpose they do so. This results in personas that are more readily usable and insightful in making design decisions. Fifth, they provide the behavioral patterns of the personas rather than presenting merely a few behavioral or demographic variables associated with them. This provides further insight for making design decisions that support the personas. Sixth, they address the limitations of the current mixed-methods approaches by identifying personas that make optimal use of both quantitative and qualitative data rather than simply identifying personas quantitatively and then enriching them qualitatively, as the current methods do.

This study breaks the dichotomy of rich versus representative personas by proposing a mixed-methodology approach to create personas for legacy systems based on the affordance actualizations, so the personas can be both rich and representative of the target user community. It uses the concept of affordances to go beyond action-based analysis of user behavior, and such insight may hopefully be of use to other scholars exploring human-computer interaction.

\section{REFERENCES}

[1] Y. Chang, Y. Lim, and E. Stolterman, "Personas: From
Theory to Practices," in Proceedings of the 5th Nordic Conference on Human-computer Interaction: Building Bridges, New York, NY, USA, 2008, pp. 439-442.

[2] J. Brickey, S. Walczak, and T. Burgess, "A Comparative Analysis of Persona Clustering Methods.," in AMCIS 2010 Proceedings, 2010, p. 217.

[3] S. Faily and I. Flechais, "Persona Cases: A Technique for Grounding Personas," in Proceedings of the SIGCHI Conference on Human Factors in Computing Systems, New York, NY, USA, 2011, pp. 2267-2270.

[4] L. Laporte, K. Slegers, and D. De Grooff, "Using Correspondence Analysis to Monitor the Persona Segmentation Process," in Proceedings of the 7th Nordic Conference on Human-Computer Interaction: Making Sense Through Design, New York, NY, USA, 2012, pp. 265-274.

[5] J. Brickey, S. Walczak, and T. Burgess, "Comparing SemiAutomated Clustering Methods for Persona Development," IEEE Trans. Softw. Eng., vol. 38, no. 3, pp. 537546, Mar. 2012.

[6] T. Adlin et al., "Putting Personas to Work," in CHI '06 Extended Abstracts on Human Factors in Computing Systems, New York, NY, USA, 2006, pp. 13-16.

[7] J. Gulliksen, B. Göransson, I. Boivie, S. Blomkvist, J. Persson, and Å. Cajander, "Key principles for user-centred systems design," Behav. Inf. Technol., vol. 22, no. 6, pp. 397-409, Nov. 2003.

[8] T. Miaskiewicz, S. J. Grant, and K. A. Kozar, “A preliminary examination of using personas to enhance user-centered design," in AMCIS 2009 Proceedings, 2009, p. 697.

[9] M. Aoyama, "Persona-and-scenario based requirements engineering for software embedded in digital consumer products," in Requirements Engineering, 2005. Proceedings. 13th IEEE International Conference on, 2005, pp. 85-94.

[10] J. Haikara, "Usability in agile software development: extending the interaction design process with personas approach," in International Conference on Extreme Programming and Agile Processes in Software Engineering, 2007, pp. 153-156.

[11] A. Seffah, C. Kolski, and D. Idoughi, "Persona Comme Outil De Design De Services Interactifs: Principes Et Exemple En e-Maintenance," in Proceedings of the 21st International Conference on Association Francophone D'Interaction Homme-Machine, New York, NY, USA, 2009, pp. 333-336.

[12] S. Faily and J. Lyle, "Guidelines for integrating personas into software engineering tools," in Proceedings of the 5th ACM SIGCHI symposium on Engineering interactive computing systems, 2013, pp. 69-74.

[13] D. Ford, T. Zimmermann, C. Bird, and N. Nagappan, "Characterizing Software Engineering Work with Personas Based on Knowledge Worker Actions," in 2017 ACM/IEEE International Symposium on Empirical Software Engineering and Measurement (ESEM), 2017, pp. 394-403.

[14] "The Trouble With Legacy Systems: An Insurance Executive's Challenges And Options." [Online]. Available: https://www.healthitoutcomes.com/doc/the-trouble-with- 
legacy-systems-0001. [Accessed: 15-Oct-2017].

[15] "Legacy systems holding back $90 \%$ of businesses," ComputerWeekly.com. [Online]. Available: http://www.computerweekly.com/news/4500248467/Legacy-systemsholding-back-90-per-cent-of-businesses. [Accessed: 15Oct-2017].

[16] "Some agencies spending 90-percent of IT budget on legacy systems — report," Fedscoop, 21-Oct-2016.

[17] "Some Agencies Spend More Than 90\% of IT Budgets on Legacy Systems, Report Finds," Nextgov. [Online]. Available: http://www.nextgov.com/cio-briefing/2016/10/idcreport-legacy-it-in-agencies/132618/. [Accessed: 15-Oct2017].

[18] R. Schach, Software Engineering, Fourth. Boston, MA: McGraw-Hill, 1999.

[19] R. L. Glass, "Frequently forgotten fundamental facts about software engineering," IEEE Softw. Los Alamitos, vol. 18, no. 3, p. 112,110-111, Jun. 2001.

[20] A. Cooper, The inmates are running the asylum:[Why high-tech products drive us crazy and how to restore the sanity], vol. 261. Sams Indianapolis, 1999.

[21] M. Johansson and J. Messeter, "Present-ing the user: constructing the persona," Digit. Creat., vol. 16, no. 4, pp. 231-243, Jan. 2005.

[22] F. Long, "Real or imaginary: The effectiveness of using personas in product design," in Proceedings of the Irish Ergonomics Society Annual Conference, 2009, pp. 1-10.

[23] J. Pruitt and J. Grudin, "Personas: Practice and Theory," in Proceedings of the 2003 Conference on Designing for User Experiences, New York, NY, USA, 2003, pp. 1-15.

[24] D. Broschinsky and L. Baker, "Using Persona with XP at LANDesk Software, an Avocent Company," in Agile, 2008. AGILE '08. Conference, 2008, pp. 543-548.

[25] J. Ma and C. LeRouge, "Introducing user profiles and personas into information systems development," in AMCIS 2007 Proceedings, 2007, p. 237

[26] P. R. Carlile, "A Pragmatic View of Knowledge and Boundaries: Boundary Objects in New Product Development," Organ. Sci., vol. 13, no. 4, pp. 442-455, Jul. 2002.

[27] A. Lindgren, F. Chen, P. Amdahl, and P. Chaikiat, "Using Personas and Scenarios as an Interface Design Tool for Advanced Driver Assistance Systems," in Universal Access in Human-Computer Interaction. Ambient Interaction, C. Stephanidis, Ed. Springer Berlin Heidelberg, 2007, pp. 460-469.

[28] T. Miaskiewicz, T. Sumner, and K. A. Kozar, "A Latent Semantic Analysis Methodology for the Identification and Creation of Personas," in Proceedings of the SIGCHI Conference on Human Factors in Computing Systems, New York, NY, USA, 2008, pp. 1501-1510.

[29] L. Columbus, "Personas Are The Future of Enterprise Apps: Lessons Learned From Scribe Software," Forbes, 2013. [Online]. Available: http://www.forbes.com/sites/louiscolumbus/2013/03/29/personas-are-the-future-of-enterpriseapps-lessons-learned-from-scribe-software/. [Accessed: 30-May-2016].

[30] J. (Jen) McGinn and N. Kotamraju, "Data-driven Persona
Development," in Proceedings of the SIGCHI Conference on Human Factors in Computing Systems, New York, NY, USA, 2008, pp. 1521-1524.

[31] R. Sinha, "Persona development for information-rich domains," in CHI'03 extended abstracts on Human factors in computing systems, 2003, pp. 830-831.

[32] C. Moser, V. Fuchsberger, and M. Tscheligi, "Using Probes to Create Child Personas for Games," in Proceedings of the 8th International Conference on Advances in Computer Entertainment Technology, New York, NY, USA, 2011, p. 39:1-39:8.

[33] M. Rahimi and J. Cleland-Huang, "Personas in the middle: automated support for creating personas as focal points in feature gathering forums," 2014, pp. 479-484.

[34] T. D. Jick, "Mixing qualitative and quantitative methods: Triangulation in action," Adm. Sci. Q., pp. 602-611, 1979.

[35] J. J. Gibson, "The Theory of Affordances," in Perceiving, acting, and knowing: toward an ecological psychology, J. B. Robert E Shaw, Ed. Hillsdale, N.J. : Lawrence Erlbaum Associates, 1977, p. pp.67-82.

[36] I. Hutchby, "Technologies, texts and affordances," Sociology, vol. 35, no. 02, pp. 441-456, 2001.

[37] S. Faraj, S. L. Jarvenpaa, and A. Majchrzak, "Knowledge Collaboration in Online Communities," Organ. Sci., Feb. 2011.

[38] P. M. Leonardi, "When Flexible Routines Meet Flexible Technologies: Affordance, Constraint, and the Imbrication of Human and Material Agencies," MIS Q., vol. 35, no. 1, pp. 147-167, Mar. 2011.

[39] A. Majchrzak and M. L. Markus, "Technology affordances and constraints in management information systems (MIS)," Encycl. Manag. TheoryEd E Kessler Sage Publ. Forthcom., 2012.

[40] Y. Yoo, R. J. Boland Jr, K. Lyytinen, and A. Majchrzak, "Organizing for innovation in the digitized world," Organ. Sci., vol. 23, no. 5, pp. 1398-1408, 2012.

[41] R. Kumar, Research Methodology: A Step-by-Step Guide for Beginners, 3 edition. Los Angeles: SAGE Publications Ltd, 2010.

[42] C. F. Michaels, "Affordances: Four Points of Debate," Ecol. Psychol., vol. 15, no. 2, pp. 135-148, 2003.

[43] H. Heft, "Affordances, Dynamic Experience, and the Challenge of Reification," Ecol. Psychol., vol. 15, no. 2, pp. 149-180, 2003.

[44] M. Mesgari and S. Faraj, "Technology Affordances: The Case of Wikipedia," in AMCIS 2012 Proceedings, 2012.

[45] D. M. Strong et al., "A Theory of Organization-EHR Affordance Actualization," J. Assoc. Inf. Syst., vol. 15, no. 2, pp. 53-85, Feb. 2014.

[46] Y. Zheng and A. Yu, "Affordances of social media in collective action: the case of Free Lunch for Children in China," Inf. Syst. J., vol. 26, no. 3, pp. 289-313, May 2016.

[47] G. C. Moore and I. Benbasat, "Development of an instrument to measure the perceptions of adopting an information technology innovation," Inf. Syst. Res., vol. 2, no. 3, pp. 192-222, 1991.

[48] J. L. Fleiss, "Measuring nominal scale agreement among 
many raters.," Psychol. Bull., vol. 76, no. 5, p. 378, 1971.

[49] J. L. Fleiss, J. C. Nee, and J. R. Landis, "Large sample variance of kappa in the case of different sets of raters.," Psychol. Bull., vol. 86, no. 5, p. 974, 1979.

[50] D. Compeau, B. Marcolin, H. Kelley, and C. Higgins, "Research Commentary-Generalizability of Information Systems Research Using Student Subjects-A Reflection on Our Practices and Recommendations for Future Research," Inf. Syst. Res., vol. 23, no. 4, pp. 1093-1109, Jun. 2012.

[51] Y. S. Lincoln and E. G. Guba, "Establishing trustworthiness," Nat. Inq., pp. 289-331, 1985.

[52] K. Charmaz, "Coding in Grounded Theory Practice," in Constructing grounded theory, SAGE, 2006.

[53] J. C. Anderson and D. W. Gerbing, "Predicting the performance of measures in a confirmatory factor analysis with a pretest assessment of their substantive validities," $J$. Appl. Psychol., vol. 76, no. 5, pp. 732-740, 1991.

[54] S. L. Jarvenpaa, "The Effect of Task Demands and Graphical Format on Information Processing Strategies," Manag. Sci., vol. 35, no. 3, pp. 285-303, 1989.

[55] R. Core Team, $R$ : A language and environment for statistical computing. $R$ Foundation for Statistical Computing, Vienna, Austria. 2015.

[56] M. Maechler et al., cluster: "Finding Groups in Data". Cluster Analysis Extended Rousseeuw et al. 2015.

[57] H. Wickham and W. Chang, ggplot2: An Implementation of the Grammar of Graphics. 2015.

[58] H. Wickham, "Reshaping Data with the reshape Package | Wickham | Journal of Statistical Software," J. Stat. Softw., vol. 21, no. 12, pp. 1-20, 2007.

[59] C. Beleites and V. Sergo, "hyperSpec: a package to handle hyperspectral data sets in R," 2015.

[60] D. Borcard, F. Gillet, and P. Legendre, Numerical Ecology with R. New York, NY: Springer New York, 2011.

[61] A. Ortiz de Guinea and J. Webster, "An Investigation of Information Systems Use Patterns: Technological Events as Triggers, the Effect of Time, and Consequences for Performance," MIS Q., vol. 37, no. 4, pp. 1165-1188, Dec. 2013.

[62] P.-N. Tan, M. Steinbach, A. Karpatne, and V. Kumar, Introduction to Data Mining, 2 edition. New York, NY: Pearson, 2013.

[63] P. Operandi, "Recommendations for Moodle users based on three case studies of university teaching," presented at the Moodlemoot, Edinburgh, 2014.

[64] M. Rosemann and I. Vessey, "Toward improving the relevance of information systems research to practice: The role of applicability checks," $M I S Q$., vol. 32, no. 1, pp. 122, 2008.

First A. Author All biographies should be limited to one paragraph consisting of the following: sequentially ordered list of degrees, including years achieved; sequentially ordered places of employ concluding with current employment; association with any official journals or conferences; major professional and/or academic achievements, i.e., best paper awards, research grants, etc.; any publication information (number of papers and titles of books published); current research interests; association with any professional associations. Author membership information, e.g., is a member of the IEEE and the IEEE Computer Society, if applicable, is noted at the end of the biography.

Second B. Author Jr. biography appears here.

Third C. Author biography appears here. 